\title{
Funes the Crate Digger: AI, Perception, and Recall
}

\author{
SCOTT HADEN CHURCH \\ Brigham Young University
}

\begin{abstract}
This essay was inspired by Jorge Luis Borges's short story about Funes, a young man with perfect perception and recall. His stunning archival ability allowed Funes to create a shorthand system for creativity, a "rhapsody of unconnected words" to stand in for his archive of memories: "Anything he thought, even once, remained ineradicably with him." There is a similar malady today, a cultural hyperthymesia, a fetish for the archive. Information is recalcitrant and will not disappear, which cheapens the value of information while amplifying the need for human attention. The art of searching through the information rapids, then, depends upon elimination perhaps more than retrieval. Human curators with inclinations toward perception and recall are needed to filter through this influx of information for the purposes of creative production. This essay theorizes the remix artist as a Borgesian librarian, a curator of archived information fragments. Through the process of "crate digging," remixers find long-forgotten samples of music and then exploit their allegorical potential. Like Funes, remix artists have an uncanny ability to perceive and to recall. Unlike Funes, rather than perceiving their talents as a curse, remix artists are model curators, exemplars of how to filter and make meaning from information overabundance. To illustrate these points, I will address the crate digging on display in two essential remix albums, DJ Shadow's Endtroducing... and J Dilla's Donuts.
\end{abstract}

\section{INTRODUCTION}

Like other articles in this issue, this essay on remix was inspired by the writings of Jorge Luis Borges. Borges seems to be an appropriate theoretical inspiration for this essay as it navigates through the contemporary practice of remix. Having been called the patron saint of Google or even the internet many times over the years, Borges has created $20^{\text {th }}$-century fiction that offers a prescient look into the digital world of the $21^{\text {st }}$ century, a world characterized by an information abundance. ${ }^{1}$ In his short story, "Funes, His Memory," the extraordinary prescience of Borges is on full display. He describes the life of Funes, a young man with perfect recall and excessive perception: "Anything he thought, even once, remained ineradicably with him."2 Funes sees this ability it as a stunning gift: "My dreams are like other people's waking hours," as well as a curse: "My memory . . . is like a garbage heap." ${ }^{3}$ Funes is burdened by his need to parlay the abundance of data housed in his brain into meaningful information. In important ways, Funes is like a human algorithm. 
The story harbors insights about the modern-day glut of information. The hero of Borges's story isn't just someone who can't forget - he notices everything, too. Funes is afflicted with excessive perception: For him, "the present was so rich, so clear, that it was almost unbearable." ${ }^{4}$ He is so perceptive, in fact, that he often has to sit alone in the dark. Mercifully, other people are able to select that which they want to hold on to, allowing the rest to slowly fade away. But Funes is tormented by an insistent abundance. Aged by this supernatural recollection, he ultimately dies an early death. Although this story is tragic, it offers some important parallels to contemporary culture. Like Funes, the digital archive is more than a repository of information; it's insatiable because it grows every day and refuses to stop. And with this relentless superabundance of information comes an associated need, for someone (or something) to sort through all the data, to make novel connections, and to bring the insights associated with those connections to the attention of people.

A similar malady to the curse of Funes exists today, a cultural hyperthymesia, a fetish for the archive. ${ }^{5}$ Information is recalcitrant and will not disappear, which cheapens its value while amplifying the need for human attention. ${ }^{6}$ The art of searching through the information rapids sometimes depends upon elimination more than retrieval. ${ }^{7}$ Therefore, there is a need for ways to sort through all the data to make it meaningful.

For the purposes of this essay, I conceptualize the notion of "meaningful data" metonymically, focusing on artistic creativity in the age of the archive. I argue that there is a type of human curator, who, like Funes, can filter through this vast amount of information. This person, the crate digger, has a predisposition toward perception and recall, cultivating these skills through the practice of remix. Crate diggers are people who regularly search through crates of vinyl records in order to find rare or interesting records that they can then incorporate into their musical projects. ${ }^{8}$ They sample portions of records and mash them up to create a familiar yet unexpected and unique track. Crate digging, then, will serve as a conceptual allegory for the process of parsing out meaningful information from mountains of data, thus demonstrating how the skills cultivated through remixing digital art are necessary for the contemporary moment.

The crate digger's skills for perception and recall not only echo those of Borges's character, they are similar to the abilities of artificial intelligence (AI). Algorithms capable of machine learning, for example, have a massive capacity for data storage and the processing power necessary to observe patterns, retain them, and then generate relevant output. Indeed, AI may eventually surpass humans in the ability to creatively recombine content in novel and surprising ways that are also palatable for human consumption. But, for the time being, crate diggers engaged in sustained searching, intuiting, discerning, and retaining are developing a special set of skills that exceed the computational creativity of machines. The crate diggers' uniquely human abilities to perceive cultural relevance derived from an understanding of historical context, their related capacity for creative restraint, and their recollection of disparate samples are all essential to this creative process.

\section{ARCHIVE CULTURE}

Google is the most conspicuous modern digital archive because of its ability to digitize and store vast amounts of information and history. ${ }^{9}$ Archiving is also a part of lived experience for many people; like Google's meticulous organization of its database, users store endless songs and pictures 
on hard drives and in the cloud. Personal devices function as archives, storing and organizing pictures, text messages, and notes..$^{10}$ Incidentally, Borges's story predicted this type of archive as well; once Funes started trying to store his recollections of his past, he became overwhelmed by the task: "Two considerations dissuaded him: the realization that the task was interminable, and the realization that it was pointless. He saw that by the time he died he would still not have finished classifying all the memories of his childhood." 11 Borges, with his fascination for the vast enormity of the archive of human knowledge, continues to offer insights about the Google age.

Because of their ubiquity, archives can overwhelm the human experience, leading to an emerging exhaustion derived from archival technology. There is a scarcity of human attention in relation to the massive amounts of information in the digital age. ${ }^{12}$ Gatekeepers certainly exist, but so does a shared mindset that if information exists, it must therefore be valuable. ${ }^{13}$ This idea is illustrated by the fact that the Library of Congress attempted to archive all of the existing user tweets in the first twelve years of the platform's operation. ${ }^{14}$ Not only does the production of digital content drastically outpace the human ability to consume it, it creates information fatigue instead of epistemic enlightenment. Neil Postman considered not only the proliferation of information, but its increasingly trivial nature to be the definition of a society at the mercy of a hegemonic "technopoly": "We are a culture consuming itself with information...cultures may also suffer grievously from information glut, information without meaning, information without control mechanisms." "15 Technologies capable of extending information in perpetuity are an asset in the folk wisdom of social media like Facebook - a website that wields the archive every time it communicates with its users.

\section{MEMORY}

Funes is an embodied example of the promises and perils of the information age; his vast perception and memory allegorizes the current problem of content oversaturation - but his perception and recall can also be considered the antidote to that problem. Funes used his memory creatively to invent a shorthand numerical system that only he understood. ${ }^{16}$ On the other hand, his gift was also a hinderance for him as he was unable to sleep, his head so full of memories that it was unbearable. Like Funes, there are people who suffer from a disorder called hyperthymesia (or HSAM - highly superior autobiographical memory). The person with HSAM does not have total recall but is simply better at retaining and recalling memories than most people. ${ }^{17}$ Like Funes, people with HSAM create vast cognitive archives for their memories, from which they draw frequently during their everyday lived experiences.

The notion of memory is one area where Borges, AI, and remix overlap. Although Borges published his short story over a decade before the term artificial intelligence was coined, the story of Funes appears to explore something similar to algorithms. ${ }^{18}$ Borges scholar David Laraway asserts that Funes's "powers of perception and recall seem...to reinforce the idea that memory might be analyzed as a mechanical processing of sense-data." ${ }^{19}$ Like Funes, artificial intelligence has the capability to perform tasks that require seeking patterns among massive data sets. Adhering to the model of artificial neural networks, AI even "learns" in a manner that is similar to the operations of the human brain. ${ }^{20}$ With humans, the brain recalls memories by extracting details from various experiences and recombining them to make them coherent. In a landmark book, F. C. Bartlett explains the recombinatory function of memory: 
Remembering is not the re-excitation of innumerable fixed, lifeless and fragmentary traces. It is an imaginative reconstruction, or construction, built out of the relation of our attitude towards a whole active mass of organized past reactions or experience, and to a little outstanding detail which commonly appears in image or in language form. ${ }^{21}$

(This can also result in false memories at times, but that's the topic for another paper.) Artificial intelligence can also be trained to extract details from that data and recombine them.

The story of Funes also can also be applied to the topic of remix. In a study they conducted on memory, Donna R. Addis and Daniel L. Schacter called attention to aspects of memory that can look like the practice of remix:

Having a jumble of details [in one's memory] is useless if they cannot be recombined and integrated appropriately. We have argued that "detail recombination" is critical to imagining coherent scenarios - the kinds of simulations one creates when thinking about experiences relevant in their daily lives. ${ }^{22}$

Like remix, memories are recombinatory. Still, memory is not the same as remix; the method by which memory reassembles fragments does not entirely align with the sampling and mashing up performed by crate diggers. The way memory works is more closely aligned with the logic of AI computational creativity (i.e., reconstruction of an event that often becomes distorted) than with remix (i.e., choosing discrete samples and then mashing them up into something new). Still, the similarities are worth noting.

\section{CRATE DIGGING}

Perhaps because memory is recombinatory, memory is important to remix artists. Like Funes, remix artists have excellent recall and excessive perception. Their uncanny ability for connection is exemplified in the practice of crate digging.

Crate digging is a practice that entails scouring record shops and flea markets for old recordings that can be repurposed. ${ }^{23}$ It's also called vinylphilia, vinyl archeology, and the fetishization of the forgotten past. ${ }^{24}$ Digging is a tedious and demanding task, to be sure; but for the crate digger, there is a joy at finding "extraordinary aural gems and grooves in the most ordinary records" drawn from "depositories of unwanted capitalist surplus." 25 Surrealist artist Andre Breton sought for the pleasures and possibilities of archived abundance: "I go [to flea markets] often searching for objects that can be found nowhere else. Old fashioned, broken, useless, almost incomprehensible, even perverse." ${ }^{26}$ Crate diggers follow a similar pursuit, using their intuition to make connections and discoveries from forgotten and unwanted sonic relics.

Digging has purposes that go beyond the aesthetic value of the art it produces. It is also about "manifesting ties to [the] hip hop deejaying tradition, 'paying dues,' educating producers about various forms of music, and serving as a form of socialization between producers." ${ }^{27}$ Because of its various cultural and aesthetic functions, it also lends legitimacy to the digger - the educated listener can tell when the remix artist has been scouring crates for rare and arcane records. ${ }^{28}$ Diggers, in other words, build their ethos from being able to make connections between samples that others have discarded, or never knew in the first place. Remix theorist Eduardo Navas describes 
remix as a "binder for the constant recycling and repurposing of material and immaterial things"; crate digging functions similarly, as a tactile practice of rummaging through crate after crate of records, searching for songs that exhibit the potential to be recycled and repurposed. ${ }^{29}$

Digging is a complex process. Writing about perhaps the most commercially successful crate digger Danger Mouse, professor of music Charles Fairchild (2014) explained the process in terms of the painstaking effort and intuition on the part of the digger, a process of searching out a massive amount of source material, then carefully listening, extracting, and reassembling: "These practices form new works that derive directly from a massive range of source texts and indirectly from a larger culture replete with influences, predecessors, and evolving sets of conventions that shape new works." 30 This practice requires a special set of skills: "Digging is much more than just the acquisition of records," explains the famous crate digger DJ Shadow; "it involves unending hours of listening, ears open to every possibility." 31 Likewise, "part of the creativity of sampling is in having a deep musical knowledge not just of certain songs but also every part of those songs." 32 In order to create, then, a crate digger not only needs to know what's in the archive, but also the precise details of each archived item, which is analogous to a heightened perception for what sounds will work in a mashup. This skill has been described as a sensitivity to certain musical pairings: "The first step for the beginning crate digger is to develop a sensibility about which records might contain material that is useful for sampling purposes...this process begins with the selective exploitation of their parents' record collections." 33 Of course, that sensibility can only develop and become refined over time.

The digger's refinement of those skills requires patience and an insatiable desire to constantly search for the perfect sample. Miho Hatori of Cibo Matto describes how the quest to discover was essential to the success of her band: "We were always buying records, searching, searching, and then sometimes we find...this one very short part, 'There, that bass line!'...To find the right one or two seconds of sound...that's a lot of work." ${ }^{34}$ Trugoy of supersamplers De La Soul explains the process in a similar way:

I could be walking in the mall and I might hear something, or in a store, something being played in the stores, and say, "Wow that sounds good." Or a sound in an elevator, you know, elevator music, "That sounds good." If it sounds good and feels good, then that's it. It doesn't matter if it was something recent or outdated, dusty, obscure, and, you know, weird. $^{35}$

DJ Shadow revels in the obscurity of the song and its potential:

When I sample something, it's because there's something ingenious about it. And if it isn't the group as a whole, it's that song. Or, even if it isn't the song as a whole, it's a genius moment, or an accident or something that makes it just utterly unique to the other trillions of hours of records that I've plowed through. ${ }^{36}$

The perfect sample for the digger is usually identified by the appropriateness of the sound for the mashup. But certain samples are appropriate because of the cultural influences they represent. ${ }^{37}$ As DJ Shadow explained:

The sampling aesthetic, and the way that I make music, is rooted in the hip-hop paradigm and the hip-hop way of thinking, which is: take what's around you, and subvert it into something that's 100 percent you, but also has a cultural connection in the way 
The sound of the song, the obscurity of the song, and the cultural relevance of the song all play a part in their appropriateness for material to be sampled.

Crate diggers, in other words, have a rare talent for what they do. Again, DJ Shadow articulated in one of the samples in his debut album what Mark Katz calls Shadow's "philosophy of music": "I would like to be able to continue to let what is inside of me, which is, which comes from all the music that I hear, I'd like for that to come out... The music's coming through me." ${ }^{39}$ Crate diggers allow the music from a lifetime of listening to flow from them. It is their keen perception and intuition that allow crate diggers to revivify old and nearly forgotten songs. ${ }^{40}$ Crate diggers, in short, have cultivated a sensibility and understanding of the material that qualifies them to create remix art.

Still, the remarkable ability of artificial intelligence (AI) to generate creative works complicates the notion that artistic creativity is an exclusively human endeavor. In the following section, I will briefly address the capabilities of AI (and its associated algorithms) for creating art and filtering information (i.e., making recommendations). The section will also consider the question of whether the machine learning capabilities of AI can compete with the human intuition that guides the creative practices of crate diggers.

\section{REMIX AND AI}

In his book and podcast Ways of Hearing, musician and writer Damon Krukowski marvels at the subversive power of crate digging. Then, he brings up an interesting point: "No one is listening to everything. It's impossible. It's not a human task on a human scale. Which means it's done by computers, using algorithms." ${ }^{41} \mathrm{He}$ then proceeds to talk about the Spotify music recommendation algorithm - with serious reservations about what these recommendation algorithms can do, given their utilitarian function:

I use Spotify's “Discover" feature, and its predictions of my musical tastes are so accurate it can be unnerving ... [but] it's not surprising ... Surprise is not the same as "discover" .. . Music recommendation services like Spotify want to give us the music we probably like. At least enough to let it keep on playing. Which is not something that sounds like nothing we've ever heard before. ${ }^{42}$

Crate diggers, however, know more than the audience does about the delightful and surprising ways in which disparate musical samples can be combined. Crate digging is an art derived from a special skill set that was developed through a systematic, sustained, and rigorous engagement with a multitude of songs. Crate digging, in some ways, is a human process that is similar to the work that AI does.

Indeed, AI can perform sophisticated tasks, many of which are more complex than the relatively simple work done by recommendation algorithms on Spotify. In the last two decades or so, AI has primarily used artificial neural networks (ANN) for creative purposes, a more "intelligent" approach than its previous model, "good old fashioned artificial intelligence" (GOFAI), which relied on rule-based symbol manipulation to work through its tasks. ${ }^{43}$ ANN is a form of bottom-up 
programming that allows "algorithms to roam the digital landscape and learn just like children." AI is more "intelligent" when it uses the method of ANN because it is largely untethered from the programmer's or developer's constant tinkering ${ }^{45}$; ANN engages in machine learning, meaning the AI is first trained on large sets of data, then is essentially allowed to proceed by locating patterns within them (i.e., forward propagation). As it begins producing output, it corrects its errors and "learns" from them as it continues (i.e., back propagation). ${ }^{46}$ It can thus be used for innovatory tasks, like (for our purposes) computational creativity in the realm of the arts.

AI, then, is already engaged in creating ars ex machina (art from machines). ${ }^{47}$ And AI appears to be quite good at this process; David Cope's Experiments in Musical Intelligence (EMI) software, for example, generated musical compositions in the manner of Mozart or Bach that were virtually impossible to distinguish from the original works. ${ }^{48}$ Cope was able to "fool" the listener with these AI compositions because of the process he programmed EMI to follow: 1) pattern matching, 2) segmentation, 3) recombination, and 4) output. ${ }^{49}$ After translating the original compositions into numerical codes, he could enter them into the software, which was trained to search for commonalities between all of them. Once producing the output, in order for EMI to avoid creating a garbled replica of a composition, Cope further refined one of the steps to reorder the musical elements "in such a way that sounds "right." 50 After the software was taught the rules to make something sound musically logical, it performed the task in an exquisite manner. Cope's EMI software was successful because it was programmed to adhere to the musical rules.

Sometimes, however, the musical rules need to be deliberately broken. This subversive act can add value to the art being created, because creative output exists in relation to what came before it. According to Margaret Boden, there are three types of human creativity: exploratory creativity, combinational creativity, and transformational creativity. ${ }^{51}$ Much of the AI-produced music is creative in an exploratory way, meaning that the compositions explore the peripheries of the rules even while upholding them. They may even use combinational creativity, which can jump from one set of rules to another, as does OpenAI's "Jukebox," which we will discuss in further detail later. But AI is limited once it enters the realm of transformational creativity, which involves deliberate rule-breaking as a creative strategy. Returning to Krukowski's concern above, algorithms do not offer novelty or the element of surprise to the listener. "Novelty" and "surprise," on the other hand, are essential to the aesthetic potency of a good remix. ${ }^{52}$ In his book The Creativity Code, mathematician Marcus Du Sautoy argues that this metric is largely lacking from computational creativity; inspired by the words of computer science pioneer Ada Lovelace, he proposes that a successful machine must create something that is "new, surprising, and of value." 53 Certainly, Cope's EMI software did create output characterized by novelty and surprise, but they were of a different variety than what crate digging can produce. EMI did surprise the listeners because of its fidelity to the source material. The compositions were novel as well because they were creative and new. However, it is debatable what actual value these machine compositions offer.

There are other intangible elements that human crate diggers provide in their remixes. Because remix depends on the audience's understanding of context and the impact of incongruous or subversive musical combinations, AI cannot - at the present time-replicate what a human crate digger can do. Essentially, machines may be adept enough to remix the archive; however, they still require the assistance of humans to replicate a sound collage similar to the work of elite crate diggers. Granted, AI can present humans with material so beyond our expectations for what remix 
sounds like that there is a genuine element of surprise. ${ }^{54}$ This AI ability presents a type of innovation that can eventually change the nature of expectations for remix. In 2001, Douglas Hofstadter, still in awe at the defeat of world champion and chess grandmaster Garry Kasparov at the virtual hands of the IBM AI named Deep Blue, marveled that AI appeared to be so superior in the game of chess: "Analogy-making is not needed, nor is associative memory, nor are intuitive flashes that sort wheat from chaff - just a tremendously wide and deep search." 55 AI simply has too much processing power and archival space to even compete with humans on this issue. In some ways, its ability to store and search is similar to that of Funes, without the sentience to feel overwhelmed by that capacity. But, also as with Funes, there are still some limitations to its ability for restraint when it reconstructs its memory in order to generate output.

This algorithmic deficiency refers to the crucial role humans play in mining the allegorical potential of remix. The "associative memory" referred to by Hofstadter does indeed matter in remix. This means that when remixers make mashups, they might opt to maintain the essence of the original sample so it can be recognized by the listeners. This type of composition, called the "selective remix," is dependent upon the cultural recognition of the song or the artist. ${ }^{56}$ One of the strengths of $\mathrm{AI}$ is that it has access to enormous amounts of data; where AI falls short, however, is in its recognition that a sample's value is subjective to both the remixer and the audience - the allegorical element of the sample. ${ }^{57}$ Both artist and audience can find the remix relevant and meaningful, but at the present time, AI cannot recognize the cultural relevance of the source material. AI can certainly experiment with various samples in its output, and if its database of songs is large enough, it can search through a nearly unlimited number of potential samples. However, it lacks the ability to discern which ratio of referentiality to use in its compositions. Crate diggers, as will be seen in the cases of DJ Shadow and J Dilla below, conscientiously use repetition and patterns in their own sound collages, refining the ratios of source material and innovation in order to enhance the mashup's referential power. Like algorithms, crate diggers extract patterns from their datasetsthey use their vast knowledge of music as forward propagation, then experiment through a trialand-error process of matching up these samples and adjusting as back propagation. But they are able to maintain the virtue of the sampled song, when needed. ${ }^{58}$ AI still needs to enhance the listenability of its creative output.

To offer an illustration-in April 2020, the Elon-Musk-funded research laboratory OpenAI launched AI software called "Jukebox" that can help users generate versions of popular songs. Drawing from a database of 1.2 million songs, Jukebox can create new songs in the style of several genres. Far advanced sonically from the midi output of David Cope's early EMI compositions, the songs generated by Jukebox actually sound like pop music recordings - the software even has the capacity to emulate vocals because it can be fed lyrics of songs. Because it is an open source algorithm, some users have begun experimenting with it by plugging in songs and allowing the AI to complete them. The few seconds of the source material appear to orient the AI, which generates music in the style of the original song. Quickly, however, the song seems to deteriorate into a bizarre approximation of the song, as if an FM radio were caught between stations. Bijan Stephen explains it this way: "It's technologically impressive, even if the results sound like mushy versions of songs that might feel familiar." 59 The output is undeniably creative, yet still lacking something essential. The developers conclude that "while Jukebox represents a step forward in musical quality, coherence, length of audio sample, and ability to condition on artist, genre, and lyrics, there is a significant gap between these generations and human-created music."60 To be sure, these AI 
remixes occasionally produce genuinely beautiful reimaginings of the original songs. They are also sometimes imbued with poignance - it's touching to listen to the AI generate vocals for deceased singers like Freddie Mercury, John Denver, and Kurt Cobain, for example. Still, these songs lack a coherent structure that could help orient the listener.

Returning to Boden's three types of human creativity might be helpful here. I interpret the Jukebox AI remixes to be heavy on combinational creativity, while David Cope's EMI compositions appear to be dependent on exploratory creativity. As of right now, however, AI compositions lack the ability to use transformational creativity. While it's possible that AI compositions might actually be so transformative that they may not even be recognized as such, this misses the point: to successfully harness the power of transformational creativity, remixed compositions need to be constrained to some degree by the meaning of the source material.

In other words, these AI songs lack a sense of understanding or appreciation of the original song. Whereas algorithms are "unconstrained by human biases and free to experiment with radical new approaches," 61 crate diggers are moored to their art precisely because of those human biases. These artists gravitate to a sample not just because of its constitutive elements and style, but also because of its historical context, level of sonic innovation, obscurity, personal influence, and recognizability. As a result, crate diggers create a sonic aesthetic that is allegorical and thus more palatable to human listeners. Again, AI is still perfecting this process; however, in the meantime, the human biases of crate diggers help reign in their creative impulses, urging them toward selfrestraint in their songs. AI, in its output, is sometimes subject to the "brute force" of its power, while crate diggers know that less is sometimes more. Admittedly, this metaphor relates more to the GOFAI model of AI than the ANN model. Still, the success of the ANN output of remix depends on the dataset upon which it is trained. It would certainly help to have a programmer with crate digger sensibilities, someone who can populate a database that is comparable to the entirety of the unique and forgotten gems that populate old, dusty record stores around the world.

Put another way, the ontology of remix depends on how it plays with the notion of authority. Making a remix is a process that must delicately balance allegory and congruity:

This [remix] tradition is held together by two things. First, it exhibits particular kinds of musical fidelity, or the relationships between the new, derivative text and its sources. These relationships create various kinds of consonance and dissonance between source texts and the new works derive from them. Second, it is held together by particular kinds of aesthetic legitimacy, or the ways in which the relationship between a new work and older works within its tradition of practice is understood and accepted. ${ }^{62}$

The deliberate subversion of genres, which can create a serious challenge to genres or songs that were once considered sacrosanct, can yield some of the best mashups: "The more disparate the genre-blending is, the better; the best mash-ups blend punk with funk or Top 40 with heavy metal, boosting the tension between slick and raw." 63 While AI can be programmed to perform generic clash with samples, it will be missing the human intuition necessary to perceive (or discover) linkages and then express them in novel ways to the audience; with remix culture, "we [can] now extend our innate creativity and insight through endlessly mutable, editable, networked spaces shot through multifarious manifestations of unlimited human expressiveness." ${ }^{4}$ 
The philosophical dimensions of this question are apparent in its semantic articulation; are machines capable of artistic expression or do they merely imitate it ${ }^{65}$ It appears that even David Cope agrees that AI is a tool to help generate human creativity. In a recent interview about AI, he admitted, "Creativity is simple; consciousness, intelligence, those are hard." ${ }^{66}$ However, media studies scholar David J. Gunkel is hesitant to dismiss AI as merely a creative tool, warning that "we should not be too quick to dismiss or explain away the opportunities opened up by these algorithmic incursions and interventions into what has been a protected and exclusively human domain." 67

So, although algorithms are increasingly capable of handling large amounts of data efficiently, they are deficient, for now, in at least one significant way: the perception of relevance that comes, uniquely, from human intuition and grasp of history. AI cannot independently recognize the cultural value of samples that are essential to creating a musical remix. Hence, AI cannot intentionally create mashups with allegorical meaning (i.e., exploiting or subverting the popularity of a certain song or genre). (Human) crate diggers, however, intuitively enact this comprehension in their remixed songs. It remains possible that AI will develop enough to eventually take this referentiality into account in its compositions; the developer could conceivably program the AI to search for this element of cultural relevancy. However, its success in performing this task will be greatly enhanced if the developer also has the skills of recall and perception that characterize the work of elite crate diggers.

\section{TWO REPRESENTATIVE ALBUMS BY CRATE DIGGERS}

Two crate diggers who exemplify these attributes of recall and perception are DJ Shadow and J Dilla, along with their essential sound collage albums Endtroducing... and Donuts, respectively.

\section{Endtroducing...}

DJ Shadow (aka Joshua Davis) has been called "the king of digging." ${ }^{68}$ Like Jorge Luis Borges, who felt it was his destiny to become a writer, Shadow feels it's his destiny to find the records he does while he's digging, calling it "karmic" when he locates a good record ${ }^{69}$ Featured in the 2001 documentary Scratch, Shadow famously talks about going to the basement of Rare Records in Sacramento to find old, dusty records. For Shadow, who had spent 11 years scouring the stacks of records in that basement at the time of filming, the basement had become his sanctuary.

In 1987, DJ Shadow started buying older records that were cheap, since nobody was interested in them. He began trying to piece together obscure source material to show people how good the grooves were. It's no coincidence that Shadow was an arts and rhetoric major in school; if rhetoric is the "art of using language to help people narrow their choices," crate digging is the art of recombining samples to attract and direct the attention of the audience. ${ }^{70}$

From those vast troves of records, DJ Shadow created a masterpiece of crate digging, a hip hop instrumental album called Endtroducing..., which he released in 1996. ${ }^{71}$ In Endtroducing..., he remixes samples in a way that immerses the listener in an otherworldly environment. He does this by sampling chimes (in "What Does Your Soul Look Like (Part IV)" and "Stem/Long Stem"), intense drum sequences, melodic keyboard bars, hypnotic chanting (in "The Number Song"), 
organ-like sounds (in "Changeling" and "Organ Donor"), and ethereal and eerie noises (in "Napalm Brain," "Organ Donor," and "Mutual Slump"). In "What Does Your Soul Look Like (Part IV)" the mashup uses a repetitive beat, punctuated by extended notes and warped, animalistic sounds. Shadow also employs real-world audio, as in "The Number Song," where it sounds as if he samples a rocket-launch countdown, or what seems to be the chatter in a control room to close the song "Changeling," or the bustle of city traffic in "Mutual Slump."

\section{Donuts}

Like DJ Shadow, J Dilla (aka James Yancey) was more than a DJ-he was a crate digger with a preternatural ear for discovering and putting rhythms together. Berklee College of Music professor Brian "Raydar" Ellis explains that Dilla "figured out how to humanize the drum machine." DJ Shadow, J Dilla did things his own way, subverting what the labels wanted him to do by avoiding sleek production techniques and sampling obscure songs, cacophonic everyday sounds, live instruments, and electronic sounds. Likewise, his songs did not use traditional song structure. ${ }^{73}$ His masterpiece of digging, Donuts (released in 2006), contains songs that are less from the selective remix tradition and more like regenerative remixes, creatively evading recognition of the source material. ${ }^{74}$

In a short documentary on J Dilla's life, his friends reminisced over their time spent digging with him, describing times when they waited for hours on end in the car, exasperated, while Dilla combed the crates for the right albums. ${ }^{75}$ Like Funes, Dilla had a knack for categorization and memory when it came to his records. His family described him as being OCD about the alphabetization of his records - but it worked for him because he could remember exactly where each record was. He cared for his collection meticulously, and as he cleaned the records, he'd put one on and listen to it from beginning to end. Later, he could recall exactly what part of the song he wanted to mix. ${ }^{76}$ Six years after Dilla died from a lethal combination of several diseases, a record store owner bought an abandoned storage unit that ended up being J Dilla's collection of 6,000 records - the spoils from his prolific crate digging. ${ }^{77}$

In Donuts, J Dilla's propensity for sampling from various genres is evident. He samples from The Jacksons, Dionne Warwick and The Isley Brothers, a track from the 1974 movie Geeta Mera Naam, The Trammps, Mountain, ESG, and The Jimi Entley Sound, among others. ${ }^{78}$ Though there's no real congruity in the genres of the sampled material, J Dilla's masterful remix technique blends these elements into something cohesive.

J Dilla's Donuts is indebted to ambience, ultimately a sound collage that sounds as if it could have been created by artificial intelligence. The press release "likened it to scanning radio stations in an unfamiliar city, a perfect description if the station's program director were playing half-broken $45 \mathrm{~s}$ found buried out back of the building." It continues:

Tempos shift gears without warning; time stretches and morphs, leaving the listener disoriented. The atmosphere can shift from sexy and lush string arrangements to aggressive, obnoxious horn loops and sinister, futurist synths, all within a five-minute span, the only constants the crackly static of a needle in the groove, and the alarm blast of a siren. ${ }^{79}$ 
The power of Donuts comes not just from Dilla's skill with finding samples and connecting them; the real story of the album is about how he transformed the samples to make them more useful, interesting, or compelling. J Dilla is the filter that recuperates the material. In his characteristically humble way, he explained the album was "just a compilation of the stuff I thought was a little too much for the MCs." 80 J Dilla's Donuts not only sampled - it spliced, extended, and transformed, recovering the original samples and repurposing them in surprising ways.

\section{AN AESTHETICS OF CRATE DIGGING}

The two albums share some aesthetic elements, particularly repetition, fragmentation, and looping. At the foundation of both albums' songs are repetitive beats or melodies. In "Midnight in a Perfect World," DJ Shadow uses a soft repetitive melody along with slow beats, dreamy piano, and lullabylike singing. Though at times it seems that there is no cohesive element connecting these fragmented songs, DJ Shadow uses record scratching to bring the listener back into the DJ space, such as in "What Does Your Soul Look Like (Pt. 1 - Blue Sky Revisit)." Thus, the remixer skillfully chooses samples and arranges them in such a way that they fit the new, adopted genre.

In Donuts, J Dilla shows off his deft remix skills by instilling an affective cadence to all of his songs. Like DJ Shadow, he does this through hypnotic use of repetition and looping and reflexive scratching. The repetition in "Waves" is ethereal, like the sound of labor in "Workinonit." In "The New," a two-tone beat that captures the attention of the listener, creating a sensation of rocking back and forth on one's heels. Although there is a potential for dissonance between the disparate genres J Dilla uses as his source material, he smooths over the jagged edges with a unifying beat and the repeated sound of scratching.

The looping theme of both albums is perhaps less apparent than the overt repetition or fragmentation in each. However, both albums are an homage to recycling and eternal life-if only in the structure of each respective album. Shadow's title, Endtroducing... implies the introduction of something new, as well as the end of something old. The ellipses after the title further complicate the point while enhancing the ambivalence. J Dilla's album begins with an "outro" and ends with an intro, a song entitled "Welcome to the Show." The sample that begins the album and the one that closes the album are the same. What's more, the title of the album implies an infinite loop, a goodness that continues forever.

The remix albums of DJ Shadow and J Dilla are by no means a comprehensive representation of the rich and varied tradition of crate digging albums - but they are representative of the creative potential of a master crate digger. Taken together, they illustrate two important takeaways from the practice of crate digging: 1) Crate diggers aim to recover the lost and forgotten, and 2) crate diggers can transform and revitalize the old and defunct. Their particular brand of remix can draw attention to those samples, along with their progenitor songs and genres. Like the librarian who points a curious patron to a little-known but beloved book, crate diggers mine the archives, then recommend the best of the abundance by appropriation, recombination, and transformation.

\section{CONCLUSION}

To conclude, we return to Borges. In another one of his essays, "The Library of Babel," Borges 
describes the universe by calling it a library. It is "composed of an indefinite, perhaps infinite number of hexagonal galleries. In the center of each gallery is a ventilation shaft, bounded by a low railing. From any hexagon one can see the floors above and below — one after another, endlessly." 81 Similar to (but beyond) the staggering volume of information deposited in the archives of the internet, Borges's library contains all the information from all human existence. The Borgesian library represents the experience of an individual who is trying to absorb the archive of all known knowledge in the universe. ${ }^{82}$ The Borgesian library signifies the need for the human curation of that endless information.

In another essay, Borges's "Total Library" is "related to atomism and combinatory analysis, to typography and to chance." 83 This language about librarians parallels the role of a crate digger. In the context of remix, each song exists on its own, but through digital combinatory practices and rearrangement - and the chance that a crate digger has access to a certain song - a new remixed song emerges. The crate digger must think through this process in order to create something worth listening to. In his "On the Nature of the Gods," Cicero foreshadows Borges's opinions on the need for deliberate action in the act of creation:

I do not marvel that there should be anyone who can persuade himself that certain solid and individual bodies are pulled along by the force of gravity, and that the fortuitous collision of those particles produces this beautiful world that we see. He who considers this possible will also be able to believe that if innumerable characters of gold, each representing one of the twenty-one letters of the alphabet, were thrown together onto the ground, they might produce Annals of Ennuis. I doubt whether chance could possibly create even a single verse to read. ${ }^{84}$

This sentiment appears to argue specifically for the need of human curation. In Borges's library, every comprehensible text is comprised of millions of strings of words. The role of the crate digger is to discover and organize atomistic information fragments into something cohesive, a new mosaic of knowledge.

To Borges, the library is a synecdoche for the infinite crates of information of the universe: "I have sometimes traveled for nights on end, down corridors and polished staircases, without coming across a single librarian." ${ }^{\circ 5}$ But there is a librarian: the crate digger. Human curators with inclinations toward perception and recall are needed to filter through this influx of information. Like the vast library from the imagination of Borges, the philosophical and thematic looping at the heart of Endtroducing... and Donuts evince the theme of infinite existence through recycling. Creative remixes "transform the viewer's state of consciousness from the static here and now to a fluid realm of possibilities," much like reading a book straight off the shelf in the Library of Babel. ${ }^{86}$

We can draw useful lessons for the $21^{\text {st }}$ century from Borges's writings. This essay proposes that we consider the crate digger to be not merely a creator of art, but a Funes for our time, a preternaturally gifted curator of archived information fragments. Like Funes, crate diggers have an uncanny ability for perception and recall. Unlike Funes, they do not perceive their talents as a curse, remix artists are model curators, exemplars of how to filter and make meaning from information overabundance. Through the process of crate digging, remixers find samples of music and then exploit their allegorical potential. Or they bring samples to the public that are long forgotten, or undiscovered gems that have no allegorical potential whatsoever. In any case, crate diggers are also 
similar to Borgesian librarians, possessing an intimate knowledge of extant material and the ability to make hitherto undiscovered connections for the audience. Human curators' perception and recall are needed to filter through the influx of information in creative ways, something that AI alone still struggles to accomplish because of its inability to discriminate between samples through intuiting their cultural relevance. In this way, AI creativity is not yet able to fulfill all of the criteria in Du Sautoy's version of the Lovelace test: although it generates creative content that is (certainly) new and (potentially) surprising, the level of value it offers is still up for debate.

\section{ENDNOTES}

1. John Durham Peters, The Marvelous Clouds: Toward a Philosophy of Elemental Media (Chicago: University of Chicago Press, 2015), 319. For other references to Borges and the internet or Google, see Martin Irvine, Web Works (New York: W. W. Norton, 1997), 122; David Laraway, Borges and Black Mirror (London: Palgrave Macmillan), 3; Zac Zimmer, "Do Borges's Librarians Have Bodies?," in Latin American Textualities: History, Materiality, and Digital Media, eds., Heather J. Allen and Andrew R. Reynolds (Tucson: University of Arizona Press, 2018), 197.

2. Jorge Luis Borges, "Funes, His Memory," in Collected Fictions, trans. Andrew Hurley (New York: Penguin, 1998), 135.

3. Ibid.

4. Ibid.

5. Angela Cirucci and Barry Vacker, Black Mirror and Critical Media Theory (Lanham, MD: Rowman \& Littlefield, 2018).

6. Richard Lanham, The Economics of Attention: Style and Substance in the Age of Information (Chicago: University of Chicago Press, 2008).

7. Peters, Marvelous Clouds.

8. Mark Katz, Groove Music: The Art and Culture of the Hip-Hop DJ (New York: Oxford University Press, 2012).

9. Peters, Marvelous Clouds.

10. Eduardo Navas, "The New Aesthetic and the Framework of Culture," Media- $N$ 8, no. 2 (2012).

11. Borges, "Funes," 136.

12. Lanham, Economics of Attention.

13. Neil Postman, "Five Things We Need to Know About Technological Change," 1998, https://www.cs.ucdavis.edu/ rogaway/classes/188/materials/postman.pdf.

14. Gayle Osterberg, "Update on the Twitter Archive at the Library of Congress," Library of Congress Blog, 2017.

15. Neil Postman, Technopoly (New York: Vintage Books, 1993), 70.

16. Borges, "Funes."

17. Linda Rodriguez McRobbie, "Total Recall: The People Who Never Forget," The Guardian, 2017.

18. "Funes, the Memorious" was first published in Spanish in 1942. The first academic conference to address "artificial intelligence" took place at Dartmouth in 1956.

19. Laraway, Borges and Black Mirror, 25. 
20. David J. Gunkel, An Introduction to Communication and Artificial Intelligence (Medford, MA: Polity, 2020), 70.

21. F. C. Bartlett, Remembering: A Study in Experimental and Social Psychology (Cambridge:

Cambridge University Press, 1995), 213.

22. Donna R. Addis and Daniel L. Schacter. "The Hippocampus and Imagining the Future: Where

Do We Stand?" Frontiers in Human Neuroscience 5, no. 173 (2012), 9.

23. Elodie A. Roy, Media, Materiality and Memory: Grounding the Groove (New York:

Routledge, 2016): 119, footnote 1.

24. Ibid., 124.

25. Ibid., 119.

26. Quoted in Krukowski, Ways of Hearing, 91.

27. Joseph G. Schloss, Making Beats: The Art of Sample-Based Hip-Hop (Middletown, CT:

Wesleyan University Press, 2014), 79.

28. Ibid.

29. Navas, "The New Aesthetic," 246.

30. Charles Fairchild, The Grey Album (New York: Bloomsbury, 2014), 63.

31. Quoted in Katz, Groove Music, 197.

32. Kembrew McLeod and Peter DiCola, Creative License: The Law and Culture of Digital

Sampling (Durham, NC: Duke University Press, 2011), 66.

33. Schloss, Making Beats, 82.

34. Quoted in McLeod and DiCola, Creative License, 22.

35. Ibid.

36. Eliot Wilder, Endtroducing...(New York: Continuum, 2005), 72.

37. Fairchild, The Grey Album.

38. Wilder, Endtroducing..., 72, emphasis added.

39. Katz, Groove Music, 197.

40. Ibid.

41. Krukowski, Ways of Hearing, 100.

42. Ibid., 103-4.

43. Gunkel, An Introduction, 85.

44. Marcus Du Sautoy, The Creativity Code: Art and Innovation in the Age of AI (Cambridge, MA: Harvard University Press, 2019), 2.

45. Ibid.

46. Ibid., 83.

47. Ibid., 196.

48. Ibid., 185.

49. Ibid., 187-8.

50. Ibid., 187.

51. Du Sautoy, The Creativity Code, 8-9.

52. Scott Haden Church, "A Rhetoric of Remix," in The Routledge Companion to Remix Studies, eds., Eduardo Navas, Owen Gallagher, and xtine burrough (New York: Routledge, 2015), 46.

53. Du Sautoy, The Creativity Code, 95.

54. Famously, when the algorithm named AlphaGo competed against top players in the game Go in 2015, its pivotal move - the one that ended up winning the game for the algorithm, it turns 
out - was one that was so surprising, many spectators assumed it was an error. Explaining, Washington Post journalist Matt McFarland said the move "was so brilliant that lesser minds-in this case humans - couldn't initially appreciate it." Quoted in Gunkel, An Introduction, 173. 55. Quoted in Gunkel, An Introduction, 171.

56. Navas, Remix Theory: The Aesthetics of Sampling (New York: Springer, 2012).

57. Navas, Remix Theory.

58. Even when the source is too obscure to recognize - as is often the case with crate diggingthey can exploit the sonic properties of the sample, placing it within the parameters of a decade or a genre.

59. Bijan Stephen, “OpenAI Introduces Jukebox, a New AI Model That Generates Genre-Specific Music," The Verge, April 30, 2020, https://www.theverge.com/2020/4/30/21243038/openaijukebox-model-raw-audio-lyrics-ai-generated-copyright.

60. OpenAI, Jukebox, https://openai.com/blog/jukebox/

61. Fan Hui, quoted in Gunkel, An Introduction, 173.

62. Fairchild, The Grey Album, 63-4.

63. Roberta Cruger, "The Mash-Up Revolution," Salon, 2003, para. 2.

64. Fairchild, The Grey Album, 60, emphasis added.

65. This question has dogged discussions about artificial intelligence since Ada Lovelace proposed it in the 19th century and John Searle famously explored it 40 years ago in his "Chinese Room" thought experiment. See Gunkel, An Introduction, 39-40.

66. Quoted in Chris Garcia, "Algorithmic Music_David Cope and EMI," Computer History Museum blog, April 29, 2015. There is more information about Cope's human-centric views on AI in Gunkel, An Introduction, 196.

67. Gunkel, An Introduction, 197.

68. Doug Pray, Scratch: A Film by Doug Pray (2001), 54:16.

69. Paul S. Piper, "For Jorge Luis Borges, Paradise Was Not a Garden But a Library." American Libraries 32, no. 7 (2001): 56-58. Wilder, Endtroducing....

70. Roderick P. Hart, Modern Rhetorical Criticism (Boston: Allyn \& Bacon, 1997), 2. With motivations similar to the objectives of rhetoric, J Dilla's remixes in Donuts hold the attention of the audience by deploying samples that quickly skip back and forth from one record to another. 71. DJ Shadow, Endtroducing..., Mo’ Wax, 1996.

72. Quoted in Vox, "How J Dilla Humanized his MPC3000," YouTube video, 2017, December 6. 73. Jordan Ferguson, Donuts (New York: Bloomsbury, 2014).

74. J Dilla, Donuts, Stones Throw, 2006. Navas, Remix Theory.

75. Fuse. "J Dilla, Crate Diggers, Fuse.” YouTube video. 26:43. March 20, 2013.

76. Ibid.

77. Ferguson, Donuts.

78. Ibid.

79. Ibid., 3.

80. Ibid., 5 .

81. Jorge Luis Borges, “The Library of Babel," in Collected Fictions (New York: Penguin, 1998), 112.

82. Piper, "For Jorge Luis Borges." 
83. Jorge Luis Borges, “The Total Library," in Selected Non-Fictions (New York: Penguin, 1999), 214.

84. Quoted in Ibid., 215.

85. Borges, "The Library of Babel," 114.

86. xtine burrough and Frank Dufour, "Creativity," in Keywords in Remix Studies, eds., Eduardo Navas, Owen Gallagher, and xtine burrough (New York: Routledge, 2018), 95.

\section{REFERENCES}

Addis, Donna R., and Daniel L. Schacter. "The Hippocampus and Imagining the Future: Where Do We Stand?" Frontiers in Human Neuroscience 5, no. 173 (2012): 1-15. doi:10.3389/fnhum.2011.00173

Bartlett, F. C. Remembering: A Study in Experimental and Social Psychology. Cambridge: Cambridge University Press, 1995.

Boden, Margaret A. Ai. New York: Oxford University Press, 2016.

Borges, Jorge Luis. "Funes, His Memory." In Collected Fictions. Translated by Andrew Hurley, 131-7. New York: Penguin, 1998.

. "The Total Library." In Selected Non-Fictions. Edited by E. Weinberger. Translated by

E. Allen, S. J. Levine, and E. Weinberger, 214-6. New York: Penguin, 1999.

. "The Library of Babel." In Collected Fictions. Translated by Andrew Hurley, 112-8. New York: Penguin, 1998.

burrough, xtine, and Frank Dufour. "Creativity." In Keywords in Remix Studies. Edited by Eduardo Navas, Owen. Gallagher, \& xtine. burrough, 92-103. New York: Routledge, 2018.

Carr, Nicholas. The Glass Cage: Automation and Us, New York: Norton, 2014.

Church, Scott Haden. "A Rhetoric of Remix.” In The Routledge Companion to Remix Studies. Edited by Eduardo Navas, Owen Gallagher, and xtine burrough, 43-53. New York: Routledge, 2015.

Cirucci, Angela M., and Barry Vacker. Black Mirror and Critical Media Theory. Lanham, MD: Rowman \& Littlefield, 2018.

Cruger, Roberta. “The Mash-Up Revolution.” Salon, 2003, August 10. https://www.salon.com/2003/08/09/mashups_cruger/

DJ Shadow. Endtroducing... Mo’ Wax MW059, 1996, compact disc. 
Fairchild, Charles. The Grey Album. New York, NY: Bloomsbury, 2014.

Ferguson, Jordan. Donuts. New York: Bloomsbury, 2014.

Fuse. “J Dilla, Crate Diggers, Fuse.” YouTube video. 26:43. March 20, 2013. https://www.youtube.com/watch?v=XL3ENrZwjmw.

Garcia, Chris. "Algorithmic Music_David Cope and EMI." Computer History Museum blog, April 29, 2015. https://computerhistory.org/blog/algorithmic-music-david-cope-and-emi/

Gunkel, David J. "Deconstruction.” In Keywords in Remix Studies. Edited by Eduardo Navas, Owen Gallagher, and xtine Burrough, 115-124. New York: Routledge, 2018.

. "Remixology: A Remix(ed) Rhetoric for the 21st Century." Journal of Contemporary Rhetoric 7, no. 2/3 (2017): 79-86.

An Introduction to Communication and Artificial Intelligence. Medford, MA: Polity, 2020.

Hart, Roderick P. Modern Rhetorical Criticism (2nd ed.). Boston: Allyn \& Bacon, 1997.

Holland, Sam. "Creativity in the Age of Artificial Intelligence." Piano Magazine: Clavier Companion 11, no. 3 (2019): 64-7.

Irvine, Martin. Web Works. New York: W. W. Norton, 1997.

J Dilla. Donuts. Stones Throw STH2126, 2006, compact disc.

Kanuck, Sean. "Humor, Ethics, and Dignity: Being Human in the Age of Artificial Intelligence." Ethics \& International Affairs 33, no. 1 (2019): 3-12. http://www.doi.org/doi:10.1017/S0892679418000928

Katz, Mark. Groove Music: The Art and Culture of the Hip-Hop DJ. New York: Oxford University Press, 2012.

Kim, David J. "Introduction: Archiving Culture." Performing Archive: Curtis + "the vanishing race.” 2018. https://scalar.usc.edu/works/performingarchive/networked-representationof-curtis-photographs-intro.

Krukowski, Damon. Ways of Hearing. Cambridge, MA: MIT Press, 2019.

Lanham, Richard. The Economics of Attention: Style and Substance in the Age of Information. Chicago: University of Chicago Press, 2008.

Laraway, David. Borges and Black Mirror. London: Palgrave Macmillan, 2020. 
McLeod, Kembrew, and Peter DiCola. Creative License: The Law and Culture of Digital Sampling. Durham, NC: Duke University Press, 2011.

McRobbie, Linda Rodriguez. "Total Recall: The People Who Never Forget." The Guardian. February 8, 2017. https://www.theguardian.com/science/2017/feb/08/total-recall-thepeople-who-never-forget.

Navas, Eduardo. "The New Aesthetic and the Framework of Culture.” Media-N 8, no. 2 (2012a).

Remix Theory: The Aesthetics of Sampling. New York: Springer, 2012b.

. "Remix." In Keywords in Remix Studies. Edited by Eduardo Navas, Owen Gallagher, and xtine burrough, 246-58. New York: Routledge, 2018.

OpenAI. Jukebox. https://openai.com/blog/jukebox/

Osterberg, Gayle. "Update on the Twitter Archive at the Library of Congress." Library of Congress Blog, Dec. 26, 2017. https://blogs.loc.gov/loc/2017/12/update-on-the-twitterarchive-at-the-library-of-congress-2/

Peters, John Durham. The Marvelous Clouds: Toward a Philosophy of Elemental Media. Chicago: University of Chicago Press, 2015.

Piper, Paul S. "For Jorge Luis Borges, Paradise Was Not a Garden But a Library." American Libraries 32, no. 7 (2001): 56-8.

Postman, Neil. Technopoly. New York: Vintage Books, 1993.

Postman, Neil. "Five Things We Need to Know About Technological Change.” Unpublished notes from a talk Postman gave in 1998. https://www.cs.ucdavis.edu/ rogaway/classes/188/materials/postman.pdf

Pray, Doug. Scratch: A Film by Doug Pray. 2001. https://www.youtube.com/watch?v=jcOUYOg-dAM

Roy, Elodie A. Media, Materiality and Memory: Grounding the Groove. New York: Routledge, 2016.

Schloss, Joseph G. Making Beats: The Art of Sample-Based Hip-Hop. Middletown, CT: Wesleyan University Press, 2014.

Stephens, Bijan. “OpenAI Introduces Jukebox, a New Model that Generates Genre-Specific Music. The Verge, April 30, 2020.

https://www.theverge.com/2020/4/30/21243038/openai-jukebox-model-raw-audio-lyricsai-generated-copyright 
Vox. "How J Dilla Humanized his MPC3000." YouTube video. 2017, December 6. https://www.youtube.com/watch?v=SENzTt3ftiU\&frags=pl\%2Cwn

Wilder, Eliot. Endtroducing .... New York: Continuum, 2005.

Zimmer, Zac. "Do Borges's Librarians Have Bodies?" In Latin American Textualities: History, Materiality, and Digital Media. Edited by Heather J. Allen and Andrew R. Reynolds. Tucson, AZ: University of Arizona Press, 2018.

\section{AUTHOR BIO}

Scott Haden Church (Ph.D., University of Nebraska-Lincoln) is an Assistant Professor in the School of Communications at Brigham Young University in Provo, Utah, USA. His research primarily uses rhetorical, critical, and aesthetic methods for examining online culture and popular culture. His work on remix has been published in The Routledge Companion to Remix Studies (Routledge, 2015), the Journal of Contemporary Rhetoric (2017), and Ancient Rhetorics \& Digital Networks (University of Alabama Press, 2018). 